\title{
Characterization of T-shaped magneto-rheological brake
}

\author{
Ilham Rizkia Nya'Ubit ${ }^{1, *}$, Gigih Priyandoko², Fitrian Imaduddin ${ }^{1}$, Dimas Adiputra ${ }^{3}$, Ubaidillah ${ }^{1}$

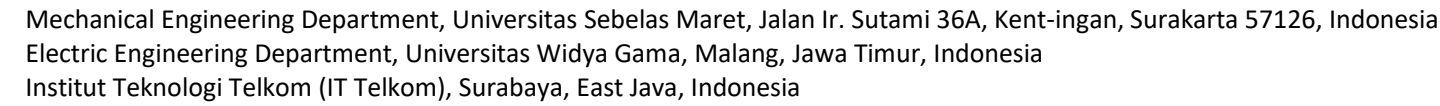

\section{ABSTRACT}

Serpentine flux T-shaped magneto-rheological brake (MRB) featuring a single coil has been proposed for reducing the needs of coil that usually implemented in conventional T-shape MR brake. Here, the use of serpentine type magnetic flux flow is the key to coil reduction. The prototype was designed and fabricated in the laboratory. The design covers analytical torque prediction, magnetic circuit simulation, and workshop drawing. While the fabricated prototype was characterized using MRB test rig equipped with torque and angular velocity sensors. The experimental work was carried out in constant speed and constant current. The torque using the analytical approach and experiment result respectively was $1.51 \mathrm{Nm}$ and $1.91 \mathrm{Nm}$ at $1 \mathrm{~A}$ current supplied. Based on the comparison between prediction and experiment results, it could be seen that the highest difference was about 20.

\section{Keywords:}

Magnetorheological fluid,

Magnetorheological brake, Torque

\section{Introduction}

Magnetorheologicals (MRs) are part of smart materials because their properties can change by magnetic field. MRs are classified as semi-active materials be-cause of only their properties were changed [1]. There are many types in MRs, including magneto-rheological fluid (MRF) that liquid phase, magneto-rheological elastomer that composite of elastomer and magnetic particle-like Waste Tire Rubber (WTR) [2] and natural rubber [3], magneto-rheological foam that foam-based and magneto-rheological gel that has a gel form.

MRF is the mixture of micron size magnetizable iron particles with non-magnetic carrier fluid [4]. It is very responsive material that could react in 10 milliseconds subjected to a magnetic field [4-5]. Its properties changes in conjunction with an increment of viscosity due to the magnetic field. This phenomenon occurs because the particles start to make a line along the flux path so that make bond like a chain $[4,6]$.

In every device, there are three basic operations of MRF. There are direct shear type, valve type, and squeeze type [5]. All of them are identic with MRF which is located between two magnetic

\footnotetext{
* Corresponding author.

E-mail address: bhrewangsa20@gmail.com
}

https://doi.org/10.37934/arms.71.1.111 
surfaces. Direct shear-type identic with two plates that one of them rotate and the another fixed. Valve type identic with two plates fixed with MRF flowing pass through them. Squeeze type identic with two plates pushed MRF to come out. In daily needs, direct shear and valve type are very popular than squeeze type.

For two decades, there were many types of research about MRF because of its responsiveness subjected to the magnetic field [1]. Besides its responsiveness, low power and tidy structure were the reason for researchers developed this type of smart material. An example of daily needs that could be used from MRF was for automotive industries [7] and health [8,9] that were developed in the form of MR brakes (MRB).

MRB is a device in mechanical field that controls brake torque using magnetic field principle. It has three basic designs, that are disc, drum, and hybrid [5]. Those designs utilize an effective area from the MRF gap to improve the performance. Disc design utilizes the annular gap, drum design utilizes the radial gap and hybrid design utilizes both annular and radial gap.

There were many ways to enhance the torque performance of MRB such as meandering flow in the core of MRB [10], add multiple discs on MRB [7], adding the number of turn wire [11], T-shaped rotor in order the path magnetic flux could reach all gap line $[8,12]$, and combining magnetic and non-magnetic material on stator or rotor which is called serpentine flux[12,13]. Serpentine flux has an advantage in increasing torque more effectively because it can manage magnetic flux path by deflecting it.

Some T-shaped MRB was proposed earlier. Hidayatullah et al. [12] made the torque prediction on design MRB with combine T-shaped type and serpentine flux on the stator. This prototype could prevent foot-drop and help the patient to therapy their ankle-foot. Its thickness and diameter were $30 \mathrm{~mm}$ and $60 \mathrm{~mm}$, respectively. It was suitable to be mounted on the passive foot ankle orthoses. The maximum torque was reached about $2.1 \mathrm{Nm}$ on $2 \mathrm{~A}$ which could sustain the patient's ankle. However, this MRB can be made more effective. Another earlier T-shape MRB was made based on those previous T-shape design, it is found that to reach a good and effective magnetization area in the MRB, usually, they took more than 1 coil for magnetic flux generator. For example, Nguyen and Choi [14] had made MRB T-shaped with two coils. It would be consuming more power due to the needs of multi-coil.

That is why in this paper, the MRB is proposed using single-coil and features serpentine magnetic flux flow. This proposed design would be effective in increasing the effective area of magnetization with lower power needs. Besides, the MRB had a lower dimension or size compared to Hidayatullah et al. [12] by reducing the thickness and gap into $26 \mathrm{~mm}$ and $0.25 \mathrm{~mm}$.

\section{Methodology}

\subsection{Design of T-Shaped Magneto-Rheological Brake}

Figure 1 shows the design of MRB. Its casing contains stator and the cover which has a screw at the end of it. The screw was made on the shaft and rotor to ensure the shaft remains connected to the rotor. AWG 28 copper wire was used to generate magnetic field. The combination of magnetic and non-magnetic materials on the stator has the function to control magnetic flux path. Magnetic material on casing and rotor let flux across the MRF gap. Non-magnetic material on bobbin used to ensure flux not reaching coil. Magnetic and non-magnetic stators are combined with the purpose to turn flux reaching the outer annular gap. MRF gap was located between rotor and stator Seals were added to prevent the leakage in MRF. The bearings were added to prevent translational motion on the shaft. Table 1 shows detailed information about parts of MRB. 


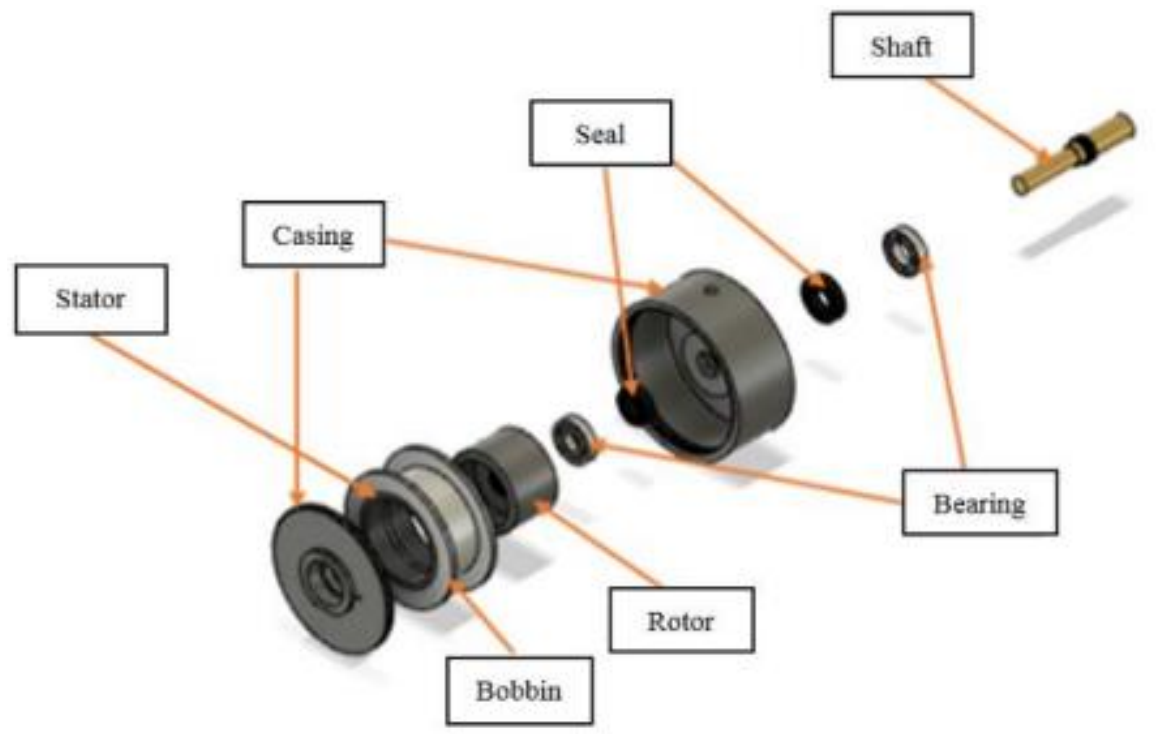

Fig. 1. Design of MRB T-Shaped Serpentine Flux

Table 1

Part List of MRB

\begin{tabular}{lll}
\hline Part & Type & Material \\
\hline Casing & Magnetic & S45C Steel \\
Stator Magnetic & Magnetic & S45C Steel \\
Stator Non-Magnetic & Non-Magnetic & Aluminum \\
Bobbin & Non-Magnetic & Aluminum \\
Shaft & Non-Magnetic & Copper \\
Rotor & Magnetic S45C & Steel \\
Coil & Non-Magnetic & Copper Wire \\
Seal & Non-Magnetic & Standard \\
Bearing & Magnetic & Standard \\
\hline
\end{tabular}

MRF is the main material for MRB. It has many types based on its function. Usually, it has microsized. The color is leaning like iron. The type of MRF used was MRF-132DG which produce by LORD Corp [15]. It is located between the casing and the rotor called MRF gap. This MRF is suitable for shear and valve type application. In no-magnetic field conditions, it had low viscosity so that MRB could rotate on the small force. Table 2 shows the properties of MRF-132DG.

Table 2

Properties of MRF-132DG

\begin{tabular}{ll}
\hline Property & Value \\
\hline Appearance & Dark grey liquid \\
Viscosity, Pa-s & 0.112 \\
Density, g/cm ${ }^{3}$ & $2.95-3.15$ \\
Solid content by weight, \% & 80.98 \\
Flashpoint, ${ }^{\circ} \mathrm{C}$ & $>150$ \\
Operating Temp., ${ }^{\circ} \mathrm{C}$ & -40 to +130 \\
\hline
\end{tabular}

\subsection{Magnetostatics simulation}

Magnetic field analysis is necessary to find how effective magnetic flux generated. This analysis is also necessary to determine magnetic flux density which used for braking torque. Reluctance for each part can be known from Equation (1) [14][15]: 
$R=\frac{L}{\mu A}$

where $L$ is distance passed by the magnetic flux in each section, $\mu$ is magnetic permeability and $A$ is an effective area from the magnetic flux path. Based on the circuit, the total of reluctance can be described in Equation (2):

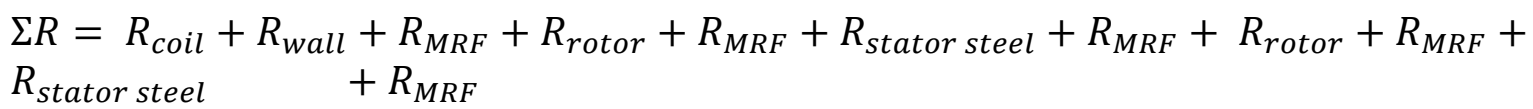

The electromotive force can be expressed in Equation (3):

$\Sigma F=\phi \Sigma R=N I$

Where $\varphi, \mathrm{N}$, and I respectively are magnetic flux, wire turn, and current passed by turn.

However, in this paper, using those equations is used to simplified the result. It should have a big error in the experimental situation. It needs a complex result that shows in every part of MRB. Therefore, the finite element method is used to fix the solution.

Finite Element Method Magnetics (FEMM) 4.2 was used for magnetic simulation [18]. FEMM is a simulation software that has functions to identify, solve, and show the result 2D problem in planar or asymmetric from magnetostatics, eddy current, and electrostatic through finite element method. The first thing to do in this simulation is drawing the design. There is a lot of materials that can be used in the FEMM library. We can also add the new material and custom it as we want. This software will define and analyze the design to record the distribution of density flux magnetic in every part of the material that cannot do in the experiment result. Fig. 2 shows the design FEMM in the asymmetric model.

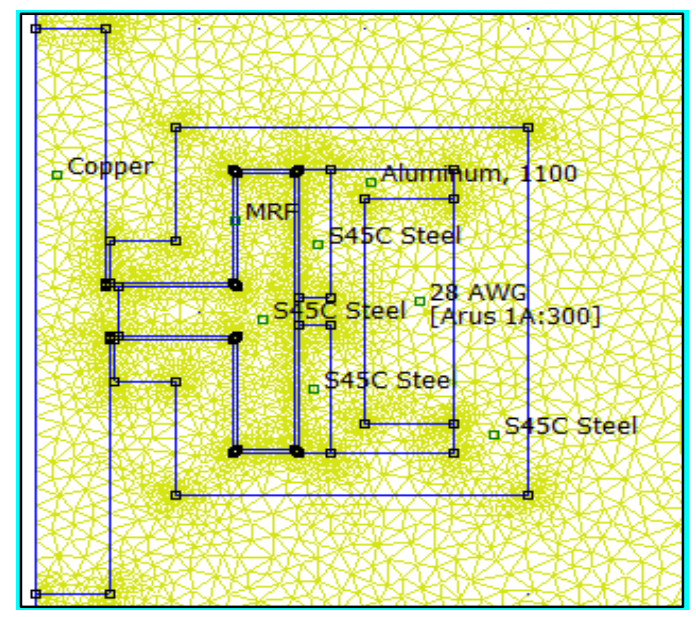

Fig. 2. Design of Simulation FEMM

\subsection{Torque analysis}

As we know that the result of braking torque from MRB is affected by shear strees between the MRB and the material in MRB. Bingham Model could predict the properties of MRF that expressed to Equation (4) [14][15]: 
$\tau=\tau_{y}(B)+\tau_{\eta}$

where $\tau$ is shear stress, $\tau y(B)$ is shear stress that depends on the magnetic field and $\tau \eta$ is shear stress that independent on the magnetic field. This equation is the combination of shear stress that onstate condition and off-state condition. Both of them can be expressed on as follows [15]:

$\tau_{y}(B)=52.962 B^{4}-176.51 B^{3}+158.78 B^{2}+13.708 B+0.1442$

$\tau_{\eta}=\eta \frac{r \dot{\theta}}{g}$

where $B$ is flux magnetic density, $\eta$ is viscosity of MRF, $r$ is radius of rotor, $\vartheta$ is the angular velocity, and $g$ is the gap of MRF. To find the braking torque in MRB, we can start from the basic torque that is shown on equation (7):

$d T=\operatorname{\tau rdA}$

where $r$ is radius from the center of rotation across $d A$. Because MRB has a round shape, the cartesian coordinate must be changed into a polar coordinate. We can use a jacobian coordinate that changes into [19]:

$d T=\tau r^{2} d r d \theta$

From equation (9), there is two differentiation that can be derivate. On this paper, design of MRB have to spin 3600 so that it has limited from 0 until $2 \pi$ that can refer to:

$T=2 \pi \int r^{2} \tau d r$

Refer (4) to (9) yield:

$T=2 \pi \int r^{2}\left(\tau_{y}(B)+\tau_{\eta}\right) d r$

Equation (10) can be separated based on on-state and off-state conditions shown respectively on equation (11) and (12):

$T_{\tau}=2 \pi \int r^{2} \tau_{y}(B) d r$

$T_{\eta}=2 \pi \int r^{2} \tau_{\eta} d r=2 \pi \int r^{2} \eta \frac{r \dot{\theta}}{g} d r$

In this case, the braking torque involves four components, those are radial T-leg (Tr1), radial Tflange $\left(T r_{2}\right)$, annular inner $\left(T a_{1}\right)$, and outer annular $\left(T a_{2}\right)$. Figure 3 shows the schematic for four components. 


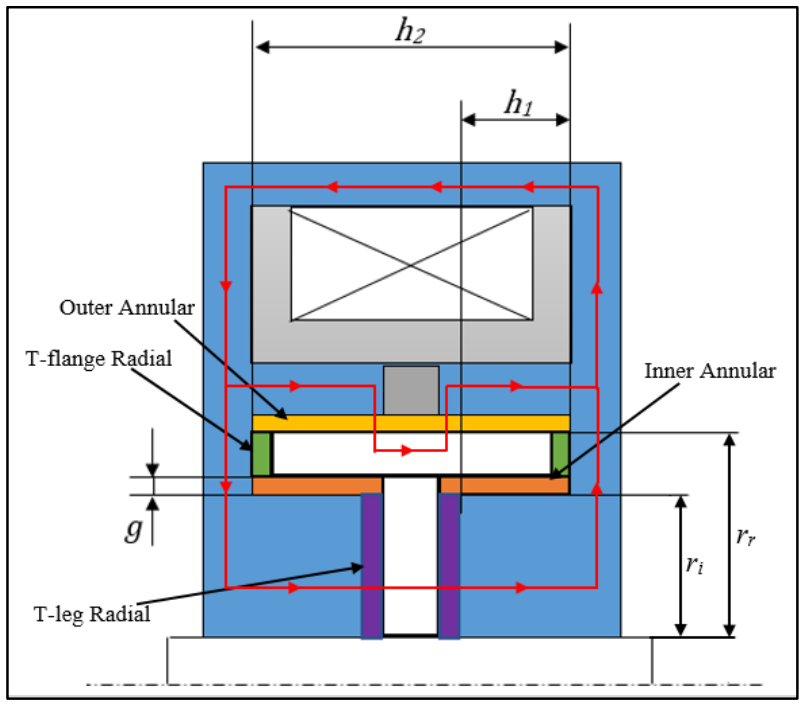

Fig. 3. Design of Simulation FEMM

In figure 3, radial T-leg has limit 0 until ri, that so torque for this component can be described offstate and on-state respectively to equation (13) and (14):

$T_{\eta \text { radial } 1}=2 \pi \int_{0}^{r_{i}} r^{3} \eta \frac{\dot{\theta}}{g} d r=\frac{\pi \eta \dot{\theta} r_{i}^{4}}{2 g}$
$T_{\tau \text { radial } 1}=2 \pi \int_{0}^{r_{i}} r^{2} \tau_{y} d r=\frac{2}{3} \pi \tau_{y} r_{i}^{3}$

For another component, the way (13) and (14) can be used to get a governing equation:

$$
\begin{aligned}
& T_{\tau_{\text {radial } 2}=}=\frac{2}{3} \pi \tau_{\tau}(B)\left(r_{r}^{3}-r_{i}^{3}\right) \\
& T_{\tau \text { annular } 1}=2 \pi \tau_{y}(B) r_{i}^{2} h_{1} \\
& T_{\tau_{\text {annular } 2}}=2 \pi \tau_{y}(B) r_{r}^{2} h_{2} \\
& T_{\eta \text { radial } 1}=\frac{\pi \eta \dot{\theta}\left(r_{r}^{4}-r_{i}^{4}\right)}{2 g} \\
& T_{\eta \text { annular } 1}=\frac{2 h_{1} \eta \dot{\theta} r_{i}^{3}}{g} \\
& T_{\eta \text { annular } 2}=\frac{2 h_{2} \eta \dot{\theta} r_{r}^{3}}{g}
\end{aligned}
$$

where $h$ is annular channel length. The base MRB dimensions on this design can be seen on table 3 .

Table 3

Base MRB dimensions

\begin{tabular}{cccc}
\hline No & Symbol & Description & Value $(\mathrm{mm})$ \\
\hline 1 & $g$ & MRF gap & 0.25 \\
2 & $r_{i}$ & Inner radius & 8.5 \\
3 & $r_{r}$ & Outer radius & 12.5 \\
4 & $h_{1}$ & Annular channel length 1 & 8 \\
5 & $h_{2}$ & Annular channel length 2 & 19 \\
\hline
\end{tabular}




\subsection{Experimental setup}

The experiment was carried out using shaft rotary torque transducer TCS-1000 KC $5 \mathrm{kgf.cm}$ $1,000 \mathrm{kgf.cm}$ or torque sensor produced by CTAplus co. It used inline method with two shafts to connect MRB and motor that suitable for measuring continuous rotating torque. It also worked on low torque with input voltage $10 \mathrm{~V}$. It consisted of a strain gage bridge that measures rotary torque. The configuration for this torque sensor is shown in Figure 4.

Torque sensor-generated analog signals that may be harmful to the monitor device if measure directly. It needed signal conditioning to make rough data from the torque sensor to be safe and legible. Data Acquisition National Instrument USB 6211 was used in this paper for signals conditioning and receiving the signals from torque sensor and encoder. It had input voltage that suitable to TCS1000 KC. Signals from data acquisition would be processed and displayed on the computer with LabVIEW software.

A DC motor was used as a driving source. It drives at a constant angular velocity of 50 RPM. The encoder was needed to ensure a constant angular velocity. Encoder Cytron B 106 was used because of small size and minimum input volt-age $5 \mathrm{~V}$. MRB had been applied at $0-1 \mathrm{~A}$ current with an increment of $0.1 \mathrm{~A}$.

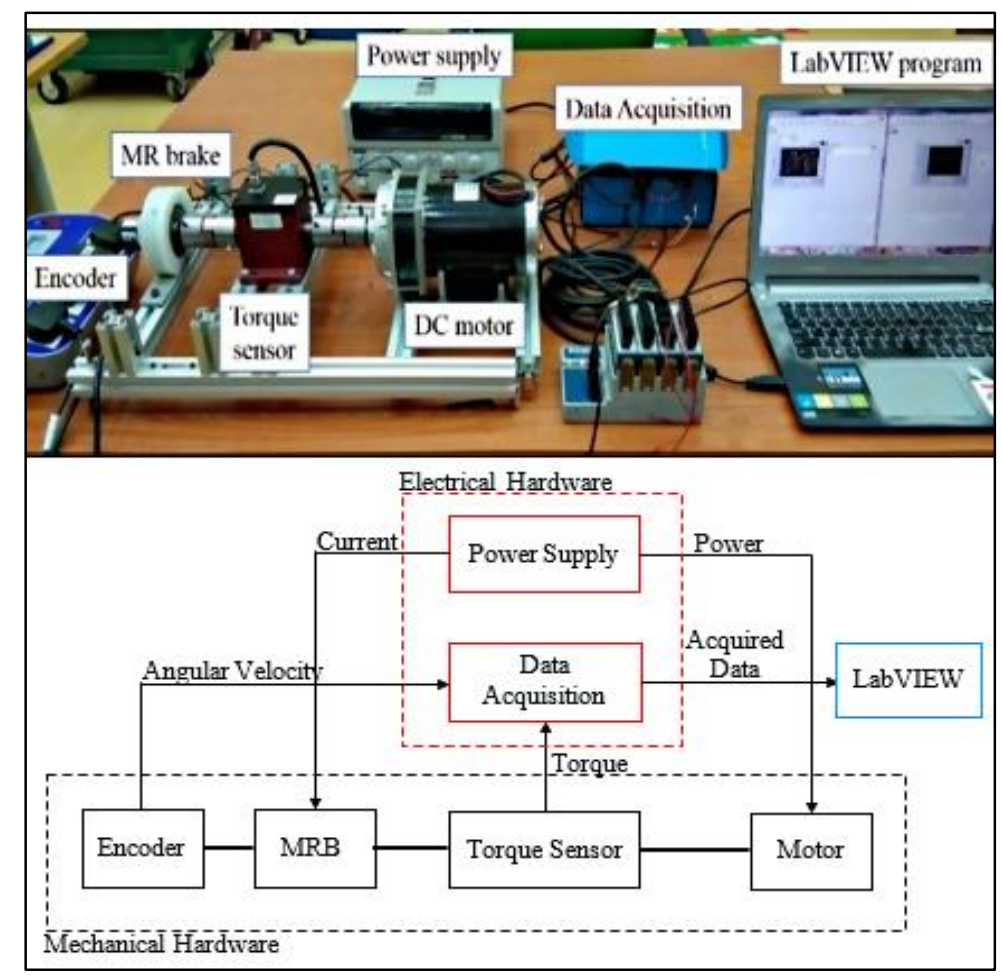

Fig. 4. Configuration of MRB test rig

\section{Results}

\subsection{Simulation result}

Figure 5 shows the model of magnetostatics simulation. Lines around MRB show the magnetic flux pathways that are only passed on magnetic material. On the outer annular, there is a turning flux groove due to the configuration of magnetic and non-magnetic materials on the stator. The red line in MRF gap is used as a reference line for making plot magnetic flux density along the length. The 
different colors show different magnetic flux density. Darker its color, greater the value of magnetic flux density.

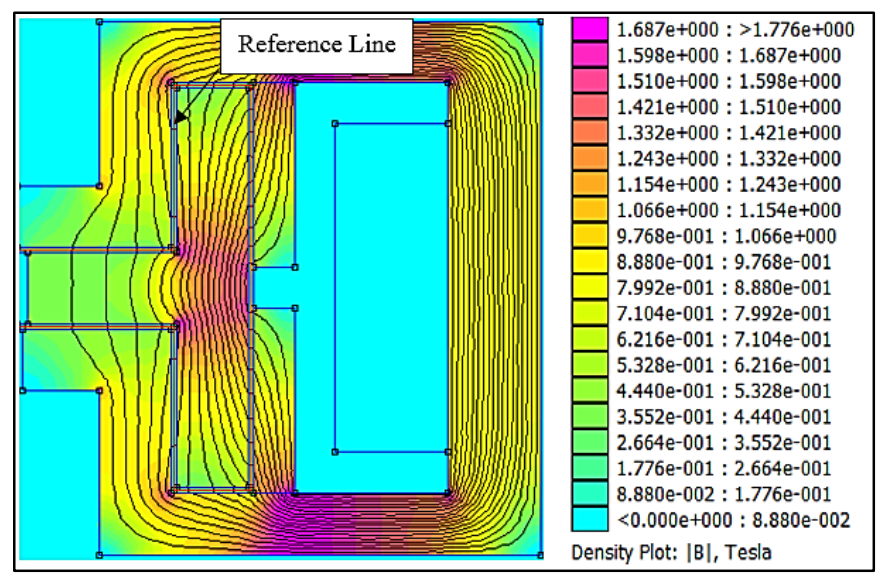

Fig. 5. Model of magnetostatics simulation

The electric current that used affects the magnetic flux density. The greater current used, the greater magnetic flux density generated. However, this increase is not the same as in the initial growth because the direction of the magnetic flux is increasingly squeezed on the wall. Figure 6 shows the distribution of magnetic flux density along the MRF gap with different variations of electric current. There are differences in each component because of the differences in path of flux and the value of magnetic flux density around the MRF gap. The largest magnetic flux density is $0.45 \mathrm{~T}$ at the peak of the outer annular. It can be concluded that outer annular gives higher contribution generated higher braking torque. Magnetic flux density obtained is used to calculate shear stress caused by the magnetic field.

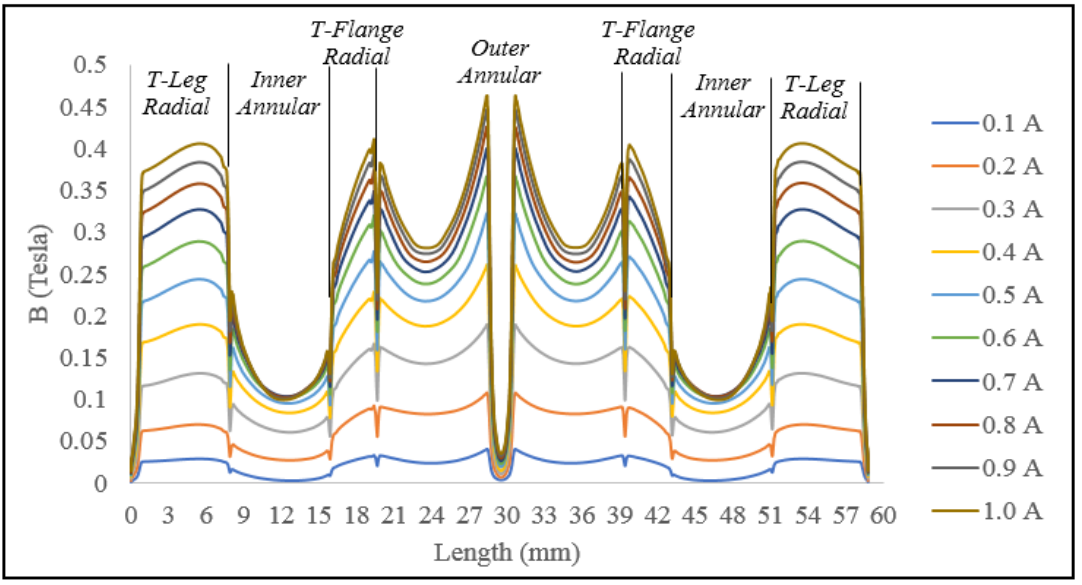

Fig. 6. Distribution of magnetic flux density along the MRF gap

\subsection{Experimental result}

The experimental work was successfully carried out according to the purpose of this paper. The braking torque from MRB recorded by TCS-1000 KC. Fig 7 shows the result of braking torque along electric current based on both torque prediction and experimental work on constant angular speed 50 RPM. 


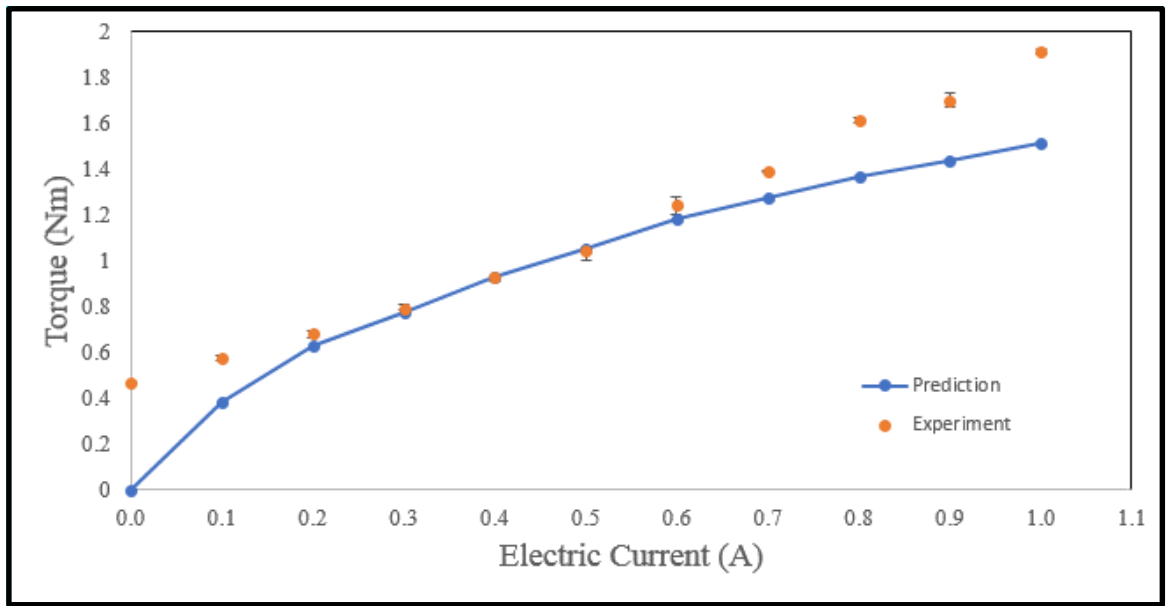

Fig. 7. Result of braking torque along with electric current

On both prediction and experimental torque, it can be noted that the increase of current supplied, braking torque also increases. However, the increment brak-ing torque is not as much as in the beginning. It was appropriate with the increment of magnetic flux density. There is small braking torque in the prediction that almost 0 on the 0 A prediction. On current $1 \mathrm{~A}$, the braking torque has the greatest value on prediction is $1.51 \mathrm{Nm}$ and the experiment is $1.91 \mathrm{Nm}$.

Table 4

Braking errors between prediction and experiment

\begin{tabular}{cccc}
\hline Current $(\mathrm{A})$ & Prediction $(\mathrm{Nm})$ & Experiment $(\mathrm{Nm})$ & Error $(\%)$ \\
\hline 0 & 0.000254565 & 0.469291276 & 99.94576 \\
0.1 & 0.379187284 & 0.571073314 & 33.60094 \\
0.2 & 0.629073046 & 0.684576616 & 8.107722 \\
0.3 & 0.778380779 & 0.79274927 & 1.812489 \\
0.4 & 0.929225234 & 0.926541621 & -0.28964 \\
0.5 & 1.054340085 & 1.047166247 & -0.68507 \\
0.6 & 1.179279703 & 1.246856944 & 5.419807 \\
0.7 & 1.274330349 & 1.393616604 & 8.559474 \\
0.8 & 1.363926183 & 1.613290009 & 15.45685 \\
0.9 & 1.435660659 & 1.698145582 & 15.45715 \\
1 & 1.514851983 & 1.911518152 & 20.75137 \\
\hline
\end{tabular}

This validation had errors. The greatest error in off-state condition $(0 \mathrm{~A})$ that reach $99.9 \%$. It might because when the MRF was putting in the gap, there was dust inside the device. The dust around the room has viscosity greater than MRF. According to (6), viscosity has an important rule to generate off-state shear stress. So, in the actual condition, the gap is not full of MRF. The vibration from the motor also causes an error. The aluminum frame cannot completely reduce vibration. Table 4 present the errors braking torque based on electric current used.

\subsection{Discussion}

This new design of MRB T-shaped had more compact structure than Hidayatullah et al.[14] with a smaller design. It would give patient installing MRB in the foot orthosis more freely. A smaller MRG gap would save more MRF so that reduces costs. The usage of smaller wire diameter could add more turn that would generate more magnetic flux. 
On FEMM result, maximum magnetic flux density was $0.45 \mathrm{~T}$. It is bigger than Ubaidillah et al.[7], but smaller than Hidayatullah et al.[14] and Nguyen et al.[16]. Some factors could affect the result. Based on design configuration, there is one component in this research and Ubaidillah [7] that is long but the area is small. It would cause reluctance to get bigger that made flux magnetic smaller. It is appropriate for (1). The materials would also affect magnetic flux density. It could be seen at the difference of magnetic flux density result from this research and Hidayatullah et al.[14].

Braking torque generated was less than $2 \mathrm{Nm}$. It is small if we compare it with another T-shaped MRB like Hidayatullah et al.[14] generated 2.1 Nm and Avraam et al.[10] $22.5 \mathrm{Nm}$. These differences cause by smaller size from another MRB design and also the result of magnetic flux density.

Braking torque also affected on the configuration. With a similar size, Ubaidillah et al.[15] only get braking torque $0.26 \mathrm{Nm}$ while this design could generate higher although magnetic flux density was smaller. This design had radius 1.6-2 times and annular channel length 2-5 times. The configuration also affects on the ability of magnetic flux to reach MRF gap. Nguyen et al.[16] and Avraam et al.[10] need double wire turn to reach almost all MRF gap while this design only use single wire turn using serpentine flux principle. It would save more power while using MRB.

In figure 7, the independent variable was electric current. It holds the main control to generates braking torque. Not only current, but also the derivation of Bingham Model at (14), (18), (19), and (20) present velocity as the independent variable that can be changed easily. But the changes in braking torque are not significant. It was appropriate in the results from Attia et al.[8].

\section{Conclusions}

Braking torque of serpentine flux T-shaped MRB had successfully carried out using a contactless torque sensor. The torque mathematical prediction has also been explained based on the geometry of MRB. The maximum braking torque for prediction was $1.51 \mathrm{Nm}$, while the experiment work achieved $1.91 \mathrm{Nm}$ at the electric current of $1 \mathrm{~A}$. The MRB had the required torque because of the combination of material and non-material that successfully maximized MRF gap. The result from FEMM simulation shown that maximum magnetic flux density was $0.45 \mathrm{~T}$ in the outer annular component. The magnetic flux could reach in almost all the MRF gap. Hopefully, this paper can be developed for getting higher braking torque and more fit for rehabilitation.

\section{Acknowledgement}

Authors thank to collaboration between Universitas Sebelas Maret and Universitas Widyagama Malang. Universitas Sebelas Maret provides inkind support and partial funding for prototype development. Universitas Widyagama provides full funding for the research through DRPM research Grant PDUPT UWG 2020.

\section{References}

[1] Sutrisno, Joko, Agus Purwanto, and Saiful Amri Mazlan. "Recent progress on magnetorheological solids: materials, fabrication, testing, and applications." Advanced engineering materials 17, no. 5 (2015): 563-597. https://doi.org/10.1002/adem.201400258

[2] Choi, H. J., S. A. Mazlan, and Fitrian Imaduddin. "Fabrication and viscoelastic characteristics of waste tire rubber based magnetorheological elastomer." Smart Materials and Structures 25, no. 11 (2016): 115026. https://doi.org/10.1088/0964-1726/25/11/115026

[3] Ahmad Khairi, Muntaz Hana, Saiful Amri Mazlan, Ubaidillah, Ku Zarina Ku Ahmad, Seung-Bok Choi, Siti Aishah Abdul Aziz, and Nurul Azhani Yunus. "The field-dependent complex modulus of magnetorheological elastomers consisting of sucrose acetate isobutyrate ester." Journal of Intelligent Material Systems and Structures 28, no. 14 (2017): 1993-2004. https://doi.org/10.1177/1045389X16682844 
[4] Mangal, S. K., and Vivek Sharma. "On state rheological characterization of MRF 122EG fluid using various techniques." Materials Today: Proceedings 4, no. 2 (2017): 637-644. https://doi.org/10.1016/i.matpr.2017.01.067

[5] Pokaad, Alif Zulfakar Bin, Khisbullah Hudha, and Mohd Zakaria Bin Mohamad Nasir. "Simulation and experimental studies on the behaviour of a magnetorheological damper under impact loading." International Journal of Structural Engineering 2, no. 2 (2011): 164-187.

[6] Imaduddin, Fitrian, Saiful Amri Mazlan, and Hairi Zamzuri. "A design and modelling review of rotary magnetorheological damper." Materials \& Design 51 (2013): 575-591.

https://doi.org/10.1016/i.matdes.2013.04.042

[7] Imaduddin, Fitrian, Muhammad Nizam, and Saiful A. Mazlan. "Response of a magnetorheological brake under inertial loads." International Journal on Electrical Engineering and Informatics 7, no. 2 (2015): 308.

[8] Attia, E. M., N. M. Elsodany, H. A. El-Gamal, and M. A. Elgohary. "Theoretical and experimental study of magnetorheological fluid disc brake." Alexandria Engineering Journal 56, no. 2 (2017): 189-200.

https://doi.org/10.1016/j.aej.2016.11.017

[9] Hudha, Khisbullah, and Hishamuddin Jamaluddin. "Simulation and experimental evaluation on a skyhook policybased fuzzy logic control for semi-active suspension system." International Journal of Structural Engineering 2, no. 3 (2011): 243-272. https://doi.org/10.1504/IJSTRUCTE.2011.040783

[10] Avraam, More, Mihaita Horodinca, Pierre Letier, and André Preumont. "Portable smart wrist rehabilitation device driven by rotational mr-fluid brake actuator for telemedecine applications." In 2008 IEEE/RSJ International Conference on Intelligent Robots and Systems, pp. 1441-1446. IEEE, 2008.

https://doi.org/10.1109/IROS.2008.4650887

[11] Gudmundsson, K. H., F. Jonsdottir, and F. Thorsteinsson. "A geometrical optimization of a magneto-rheological rotary brake in a prosthetic knee." Smart materials and Structures 19, no. 3 (2010): 035023.

https://doi.org/10.1088/0964-1726/19/3/035023

[12] Imaduddin, Fitrian, Saiful Amri Mazlan, Hairi Zamzuri, and Abdul Yasser Abd Fatah. "Testing and parametric modeling of magnetorheological valve with meandering flow path." Nonlinear Dynamics 85, no. 1 (2016): $287-302$. https://doi.org/10.1007/s11071-016-2684-6

[13] Kikuchi, Takehito, and Keigo Kobayashi. "Design and development of cylindrical MR fluid brake with multi-coil structure." Journal of System Design and Dynamics 5, no. 7 (2011): 1471-1484.

https://doi.org/10.1299/jsdd.5.1471

[14] Hidayatullah, Faishal Harish, Endra Dwi Purnomo Ubaidillah, Dominicus Danardono Dwi Prija Tjahjana, and Ilham Bagus Wiranto. "Design and simulation of a combined serpentine T-shape magnetorheological brake." Indonesian Journal of Electrical Engineering and Computer Science 13, no. 3 (2019): 1221-1227. https://doi.org/10.11591/ijeecs.v13.i3.pp1221-1227

[15] Ubaidillah, Wibowo, D. Adiputra, D. D. D. P. Tjahjana, M. A. A. Rahman, and S. A. Mazlan. "Performance prediction of serpentine type compact magnetorheological brake prototype." AIPC 1788, no. 1 (2017): 030032. https://doi.org/10.1063/1.4968285

[16] Hung, Nguyen Q., and Choi S. Bok. "Optimal design of a T-shaped drum-type brake for motorcycle utilizing magnetorheological fluid." Mechanics based design of structures and machines 40, no. 2 (2012): 153-162. https://doi.org/10.1080/15397734.2011.616479

[17] C. Load, "MRF-132DG Magneto-Rheological Fluid," Lord Prod. Sel. Guid. lord Magnetorheol. fluids, vol. 54, no. 2, p. 11, 2011.

[18] D. Meeker, “Finite Element Method Magnetics Version 4.2 User Manual,” p. 158, 2010, [Online]. Available: http://www.femm.info/Archives/doc/manual42.pdf.

[19] L. Falcgo, “Design of a Magnetorheological Brake System," Evolution (N. Y)., no. June, p. $2000,2002$. 